transported to the surface. A steady state is set up in which the change in the depletion layer charge is determined by the relative rates at which holes can be fed from $\mathrm{O}_{\text {ads }}$ to $\mathrm{R}$ in solution and the rate at which they can be supplied by the electrode. If the former rate is slow, the overall quantum efficiency will be very low.

In attempting to overcome these problems, a great deal of effort has been invested in pursuing a detailed understanding of the fundamental surface processes on semiconductors in contact with aqueous and non-aqueous electrolytes. In parallel with this work, novel methods of chemically modifying the surface to improve the quantum efficiency have been explored, and a large amount of phenomenological information gathered. Heller's group at Bell Laboratories has been especially active in this field, and has made considerable progress in reducing the effects of corrosion and surface-state recombination in cells based on aqueous electrolytes. The technological price has, however, been severe; water is a highly corrosive solvent, partly because of its excellent solvating properties, and complex measures for protecting the surface, involving various chemisorbed metal ions, have had to be developed.

These technological difficulties have had a rather discouraging effect on aqueous photovoltaic work. In an effort to avoid some of the problems, several groups around the world have begun programmes of research into non-aqueous electrolytes. Initially, behaviour was found which suggested that chemisorption of the redox couples used was very common, and it was suggested that these cells would therefore have an intrinsic limitation to their efficiencies. However, it now appears from the work of Gronet and Lewis, reported in this issue, that no such intrinsic limitations exist. By using n-type $\mathrm{GaAs}_{1-x} \mathrm{P}_{x}$ electrodes and extremely straightforward cell design, they have obtained efficiencies of over 13 per cent. This is a remarkable result especially as, by the authors' admission, the cell is quite unoptimized. There can be little doubt that this result will lead to a considerable reassessment of liquid junction photovoltaic devices and the obviously urgent task is now to investigate the use of polycrystalline electrodes to see whether the real advantages of such cells can be realized.

\title{
Keratinocyte culture club
}

\section{from Fiona $M$. Watt}

IN recent years new techniques for the cultivation of epidermal cells (keratinocytes) have generated enormous interest among clinicians and biologists alike. Dermatologists are attracted by the possibility that keratinocytes from patients with skin disorders may behave abnormally in vitro. Given the clinical importance of squamous cell carcinomas, tumour biologists are discarding fibroblasts in favour of keratinocytes for many in vitro models of transformation and carcinogenesis. Keratinocytes appeal to the cell biologist too: as a system for studying terminal differentiation and population kinetics; for investigating basement membrane synthesis and the structure and function of keratin filaments. Scientists with these diverse interests gathered recently at a symposium on keratinocyte biology* which turned out to be lively and thoughtprovoking.

Methods of cultivating keratinocytes seem to proliferate more rapidly than the cells themselves, but generally fall into two categories: first, relatively simple systems for serial passage of cells, in which some of the properties of intact epidermis are retained; second, more elaborate attempts to reconstruct true epidermis in primary culture by approximating a normal "'Biology of the Keratinocyte In Vitro', 32nd Annual
Symposium on the Biology of Skin, was held at Gieneden Beach, Oregon on 10-14 October 1982 epidermal environment. Of the first group, the most successful is undoubtedly that of Rheinwald and Green (Cell 6, 331; 1975), in which human keratinocytes can be grown for many generations on a feeder layer of $3 \mathrm{~T} 3$ cells. There have been several attempts to eliminate the requirement for feeder cells and a new chemically defined medium for human keratinocytes seems quite promising (S. Boyce, University of Colorado). It is harder to persuade mouse keratinocytes to proliferate in vitro, and consequently most cultures are seeded at high density. A low level of calcium ions $(<0.1 \mathrm{mM})$ enhances proliferation of newborn mouse epidermal cells $(H$. Hennings, NCI), but as this prevents stratification, normal terminal differentiation, in which a steady state is achieved between basal cell division, suprabasal differentiation and cell shedding, is not observed.

The histological appearance of cultured epidermis can be improved by growth on a 'dermal equivalent' - a collagen gel containing fibroblasts (E. Bell, MIT). Further attempts to mimic the normal environment of epidermal cells include culturing at an air-liquid interface, feeding cells from below and providing a growth

Fiona M. Watt is Head of the Molecular Cell Biology Laboratory at the Kennedy Institute of Rheumatology, 6 Bute Gardens, London W6 $7 D W$. substrate of basement membrane components, all of which can improve the differentiated morphology of primary cultures (M. Prunieras, Fondation Rothschild; I. Mackenzie, University of Iowa).

In order to analyse normal differentiation or to define abnormalities in disease, it is essential to have good biochemical markers of keratinocyte differentiation; morphological criteria are not cnough. Late in terminal differentiation an intracellular envelope of protein cross-linked by transglutaminase is formed. So far, two envelope precursors have been identified and solemnly named - involucrin ( $R$. Rice, Harvard University) and keratolinin (not to be confused with keratohyalin) (L. Peterson, Oregon Health Sciences University). While it is still too early to say how many envelope precursors there are and how they are related, individually they provide good markers of terminal differentiation. Lectin binding by keratinocytes changes during differentiation, reflecting altered membrane glycosylation (P. Elias, VA Medical Center, San Francisco; F. Watt, Kennedy Institute). Such changes in keratinocyte surface properties might influence cell recognition and adhesion and could account for the sorting out of differentiating cells during stratification. Monoclonal antibodies to keratins reveal patterns of keratin synthesis characteristic of different stages of differentiation (T.-T. Sun, New York University). With elegant new STEM and linear mass density studies on keratin filament structure (P. Steinert, $\mathrm{NCI}$ ) and with amino acid sequences of individual keratins obtained by gene cloning (E. Fuchs, University of Chicago; D. Roop, NCI), the biological significance of keratin heterogeneity may at last become clear.

Certain skin disorders, such as congenital ichthyosis, are characterized by distinct ultrastructural abnormalities which may continue to be expressed in vitro (I. Anton-Lamprecht, Institute for Ultrastructure Research, Heidelberg). However, good morphological criteria of disease are unusual in keratinocyte cultures, and many studies of potential clinical relevance are hampered by failure to exploit the known biochemical markers of normal terminal differentiation instead. This will surely change before long: it is exciting to learn, for example, that human cervical displasia is correlated with a decrease in involucrin synthesis, as this should be amenable to analysis in culture (R. Rice).

Corrigendum
In the News and Views article
'Transformation and gene organization in
Drosophila' (Nature $\mathbf{3 0 0}, 15 ; 1982$ ), the work
on cell division mutants (penultimate
paragraph) was attributed solely to B. Baker's
l.a Jolla laboratory. Since its inception, this
rescarch has in fact been done in collaboration
with the laboratory of M. Ciatti (Rome).

